\title{
OBITUARIO
}

\section{ARIEL SANTANA ÁGUILA}

(1952-2011)

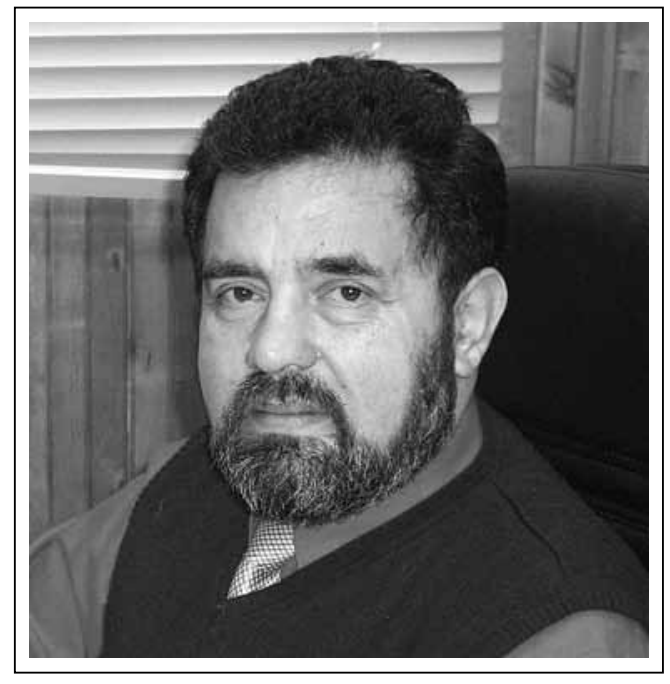

El día miércoles 08 de junio del 2011 falleció en la ciudad de Punta Arenas el Ingeniero Ariel Santana Águila, quien se desempeñara como investigador en el Instituto de la Patagonia desde 1978 hasta la fecha; y como académico de la Universidad de Magallanes a partir de 1985.

Ariel Santana, nacido en Punta Arenas, cursó sus estudios secundarios en la Escuela Industrial Superior de la misma ciudad, con especialidad de Máquinas y Herramientas, para proseguir más tarde con sus estudios en la Universidad Técnica del Estado (actualmente Universidad de Magallanes). Aquí, cursó la carrera de Ingeniería de Ejecución en Mecánica, con mención en Termofluidos, egresando de ésta a fines del año 1977.

Llega al Instituto de la Patagonia a mediados del año 1977 con la intención de poder realizar su tesis de ingeniería, contactándose en ese entonces con el geógrafo e investigador Enrique Zamora; y se integra casi de inmediato a media jornada con cargo a la Sección Geografía del Departamento de Historia y Geografía y como ayudante del área de Climatología que recién se había abierto aprovechando la existencia de la estación climática "Jorge Schythe" que funciona desde mediados del año 1970 en el Instituto de la Patagonia. 
En sus inicios Ariel se incorpora a las actividades de la Sección, trabajando en procesar gran cantidad de información climática que se reunía de distintos puntos geográficos de la región, como así también preparando los informativos diarios que se proporcionaban a través de distintos medios de comunicación.

En 1983 asume la jefatura del Laboratorio de Climatología y en especial la investigación de los estudios climáticos del Instituto. En esa misma época se instala el Observatorio Astronómico "Cruz del Sur" por gestión del entonces director Mateo Martinic, y el ingeniero Santana asume su cuidado y uso, con un sello marcado de informar y capacitar a la comunidad magallánica de los fenómenos y eventos astronómicos que podían ser visibles a través de su telescopio.

Con la incorporación del Instituto de la Patagonia a la Universidad de Magallanes en el año 1985, Ariel desarrolla la faceta de profesor universitario en diversas asignaturas tales como: profesor de laboratorio de Mecánica de Sólidos, Introducción a la Astronomía, Astronomía en asignatura de Física, Percepción Remota, impartidas en numerosas carreras de la Universidad. Durante su vida profesional realizó variados cursos de especialización a nivel nacional e internacional entre los que destacan; climatología, astronomía, teledetección y sistemas de información geográfica, lo cual lo transformó en un investigador visionario e innovador.

Donde entregó sus mayores conocimientos como climatólogo fue en la docencia de dicha especialidad en la carrera de Licenciatura en Ciencias Biológicas (Climatología entre 1994-2004); Carrera de Técnicos Agropecuarios (Agroclimatología entre 1990-2004), e Ingenieros de Recursos Naturales y Agropecuarios (Agroclimatología entre 1994-2005); en la que daba un fuerte énfasis en la climatología regional de Magallanes.

Como investigador siempre fue de su interés fomentar la revista Anales del Instituto de la Patagonia, registrando en él una gran cantidad de resúmenes y publicaciones científicas todas centradas en el estudio del clima de la región de Magallanes, generando a la vez gran parte del conocimiento que se tiene de ésta en la actualidad; donde Ariel fue sin duda, un pionero y el gran experto en esta zona austral.

Nicolás Butorovic Carlos Olave 